\title{
EL TESTAMENTO DEL LIBREPENSADOR JOSÉ COLOM VÍCTOR
}

(1854-1913)

\section{SALVADOR DAZA PALACIOS ${ }^{1}$}

RESUMEN: José Colom Víctor (1854-1913) fue un personaje heterodoxo y complejo en una época de grandes convulsiones ideológicas. Republicano, ateo, seguidor de la escuela moderna de Ferrer y Guardia y de amplia formación, pertenecía a una tradicional familia sanluqueña en la que el conservadurismo era un signo más de su identidad genealógica. Hombre de cultura y gran nivel económico, se enfrentó a su familia y a las élites burguesas y políticas de su pueblo. A su fallecimiento dejó una mediana fortuna que quiso aplicar a la creación de una Fundación que demostrase la falsedad de todas las religiones. Más de cien años después, sus intenciones, plasmadas en su testamento, aún no se han hecho realidad.

PALABRAS CLAVE: Librepensamiento, José Colom Víctor, Sanlúcar de Barrameda, escuelas laicas, republicanismo, laicismo.

\section{THE TESTAMENT OF FREETHINKER JOSÉ COLOM VÍCTOR}

(1854-1913)

\begin{abstract}
José Colom Víctor (1854-1913) was a heterodox and complex character at a time of great ideological convulsions. Republican, atheist, follower of the modern school of Ferrer and Guardia and extensive training, belonged to a traditional family of Sanlúcar de Barrameda (Cádiz) in which conservatism was another sign of his genealogical identity. Man of culture and great economic level, he faced his family and the bourgeois and political elites of his people. At his death he left a medium fortune that he wanted to apply to the creation of a Foundation that demonstrated the falsity of all religions. More than a hundred years later, his intentions, embodied in his will, have not yet come true.
\end{abstract}

KEYWORDS: Freethinking, José Colom Víctor, Sanlúcar de Barrameda, secular schools, republicanism, secularism.

\footnotetext{
${ }^{1} \mathrm{El}$ autor quiere dejar constancia de su agradecimiento al historiador Santiago Pérez del Prado, quien le facilitó diversos apuntes personales que han enriquecido este trabajo. También a Nieves García Ortiz, directora del Archivo Municipal de Sanlúcar de Barrameda, por su ayuda en la localización de diversa documentación pública.
} 


\section{Contexto político e ideológico}

Nació el personaje objeto de nuestro estudio, José Colom Víctor, en Sanlúcar de Barrameda, un 17 de diciembre del año en que estalló en España la Revolución de 1854, también conocida como la Vicalvarada, que supuso el fin de la década moderada (1844-1854), dando paso al bienio progresista (1854-1856). En noviembre de ese mismo año, las Cortes Constituyentes iniciaron el debate de una nueva Constitución, en la que se incluyeron algunos artículos que abrían la puerta a una tímida tolerancia religiosa, pues, aunque la nación se obligaba a sostener «el culto y los ministros de la religión católica que profesan los españoles», se establecía que nadie sería perseguido «por sus opiniones y creencias religiosas, mientras no las manifieste por actos públicos contrarios contra la religión ${ }^{2} \gg$. Esto desencadenaría las protestas de los obispos españoles y la ruptura de relaciones con el Vaticano. La aprobación en 1855 de la "Ley de desamortización general civil y eclesiástica", más conocida como la Desamortización de Madoz, había provocado presiones por parte de la jerarquía católica a la reina Isabel II, que expresaba su temor a perder la corona. Pues era una corona en disputa por la división del monarquismo en dos frentes irreconciliables: los partidarios isabelinos y los carlistas, defensores de la más pura ortodoxia tradicionalista y legitimista, partidarios de Carlos María de Borbón. Una división que provocó a lo largo del siglo tres guerras civiles en las que el protagonismo eclesiástico quedó en evidencia ${ }^{3}$. La participación activa de muchos religiosos en la vida política e incluso en los frentes bélicos produjo un rechazo casi generalizado de la opinión pública, que comprobaba como el clero abandonaba su mansedumbre sacerdotal y trataba de ocupar espacios de disputa partidista que no le correspondían. La sensación de que frailes y sacerdotes gozaban de impunidad para cometer muchos desmanes también ocasionó grandes críticas entre el pueblo y determinados dirigentes del progresismo, partidarios de un cambio radical en la sociedad española para que esta evolucionara hacia una mayor independencia ideológica.

Tal como afirma Revuelta González, el anticlericalismo histórico ${ }^{4}$ aparece estrechamente ligado a la revolución y, por tanto, a las fuerzas radicales izquierdistas. Según

\footnotetext{
2 Artículo 14 de la Constitución de 1856, que, discutida y votada por las Cortes de 1854-56, no llegó a promulgarse al restablecerse la de 1845 tras el golpe «contrarrevolucionario» del general O’Donnell en julio de 1856.

${ }^{3}$ CLEMENTE, Josep Carles: Los carlistas. Madrid, Istmo, 1990, pp. 45-46. PALACIO ATARD, Vicente: Manual de Historia de España: Edad contemporánea, I (1808-1898), Madrid, Espasa Calpe, p. 509.

${ }^{4} \mathrm{El}$ anticlericalismo histórico, según Revuelta González, significa un ataque al clero, entendiendo por clero no sólo las personas pertenecientes al estamento o clase clerical, sino también la ideología que representan, las instituciones que dominan, y la influencia que ejercen en la vida social y política. (REVUELTA GONZÁLEZ, Manuel: "El anticlericalismo español en el siglo XIX", en Religión y sociedad en España (siglos XIX y XX) [en línea]. Madrid, Casa de Velázquez, 2002 (Consultado el 24 de septiembre de 2020. Disponible en Internet: $<$ http://books.openedition.org/cvz/2766>
} 
Revuelta, «las revoluciones políticas pretenden derribar el edificio de unos regímenes que tenían en una Iglesia privilegiada uno de sus soportes fundamentales. Dado que el predominio eclesiástico (clericalismo) estaba unido al régimen que se quería combatir, el ataque a la institución eclesiástica (anticlericalismo) era una secuela inexcusable en la lucha revolucionaria por el poden».

Durante todo el Antiguo Régimen, en la corona de España habían confluido el poder político y el religioso. «Monarquía y religión católica -como apunta Louzao Villar- fueron los elementos que aglutinaron a los españoles durante la Edad Moderna» ${ }^{5}$. Pero desde 1820, con el acceso al poder del liberalismo, la Iglesia se fue convirtiendo en uno de los principales enemigos del estado liberal, por lo que, en consecuencia, la Santa institución arremetió con dureza contra él, inmersa plenamente en una lucha política en la que obispos y presbíteros eran protagonistas y pretendían liderar la opinión pública. Tradicionalismo e Iglesia conformaron un discurso «donde el liberalismo era nocivo, pernicioso y ponía en serio peligro la unidad católica española».

A la jerarquía católica no le quedó más remedio que aceptar el régimen político liberal, aunque ideológicamente lo combatía entre sus fieles. En la segunda mitad del siglo la Iglesia buscó con ansiedad la identificación de los símbolos del nacionalismo con su propia ideología. Estaba naciendo el nacional-catolicismo. Todo proyecto de mejora de las estructuras políticas y sociales del país debían pasar necesariamente por la conservación y el reforzamiento de la fe católica, apostólica y romana, y cualquier avance hacia el laicismo, según los modelos europeos, llevarían forzosamente al país a la ruina y a la destrucción.

Frente a estos principios inamovibles de los principales y poderosos sectores del clero hispánico, se encontraban los defensores de la laicidad del Estado. El gran enfrentamiento severo se produjo cuando el republicanismo alcanzó el poder político tras la crisis monárquica que llevó a la reina Isabel II al exilio ${ }^{6}$. La experiencia resultó traumática para la Iglesia, así que a partir de la restauración monárquica de 1875 la identificación de la sacra institución con el Trono hereditario de los Borbones se afianzó aún más. La organización mejoró, pues se movilizó a los feligreses como militantes de una fuerza ideológica que, a través del voluntariado, se implicaron en la defensa del credo católico en todos los ámbitos públicos, prestando especial atención a la enseñanza, las publicaciones, y todo tipo de actividades divulgativas, asociaciones y movimientos de caridad.

${ }^{5}$ LOUZAO VILLAR, Joseba: "La recomposición religiosa en la modernidad: un marco conceptual para comprender el enfrentamiento entre laicidad y confesionalidad en la España contemporánea", En Hispania Sacra, LX-121, enero-junio 2008, 331-354. La cita, en la p. 345.

${ }^{6}$ SAN FELIPE ADÁN, M. Antonia: "Noticias sobre clericalismo y anticlericalismo en Calahorra a partir del siglo XIX según el Libro Negro de don Pedro Gutiérrez Achutegui”. En Kalakorikos, 13, 2008, pp. 241-284. 
Pero el anticlericalismo y el republicanismo izquierdista seguía trabajando por neutralizar la influencia de obispos y párrocos en la mentalidad colectiva. Entre 1901 y 1913 el enfrentamiento con los clericales se agudizó.

En 1902 se crea la Federación Internacional de Librepensadores en España, Portugal y América. El librepensamiento surge como una vuelta de tuerca más hacia la liberación del hombre del yugo de la Religión. Rechaza todo dogmatismo religioso o político y confía en la razón para encontrar la verdad en un clima de tolerancia y diálogo. Su apóstol principal en España fue, desde 1883, el semanario Las Dominicales del Libre Pensamiento (1883-1909), editado por Fernando Lozano. Asociado a la Institución Libre de Enseñanza, la entidad de mayor trascendencia (1876-1936), una iniciativa propiciada por ilustrados, como Giner de los Ríos, Azcárate, Salmerón, Machado o Cossío, entre otros, el movimiento se muestra muy interesado en conseguir una formación laica, libre del protagonismo eclesiástico, que entonces monopolizaba la educación nacional de los niños españoles. Este movimiento y sus representantes, como Ferrer Guardia, serían perseguidos hasta la muerte por el sector más conservador del país. Ferrer perteneció a la masonería y ésta «veía en la intolerancia católica el mayor enemigo del progreso, y resultaba fácil interpretar la ejecución de Ferrer como una venganza clerical contra el impulsor de una enseñanza laica» y la caída del gobierno de Maura «como un triunfo de las fuerzas progresistas ${ }^{7} »$. El pedagogo librepensador Ferrer y Guardia promovió en Barcelona la primera escuela laica moderna, que después se fue extendiendo por toda la geografía nacional. El objetivo esencial de este proyecto era «educar a la clase trabajadora de una manera racionalista, secular y no coercitiva ${ }^{8}$. Pero Ferrer fue acusado de promover los sucesos de la Semana Trágica de la capital catalana en 1909 y condenado a muerte.

El gobierno presidido por el liberal José Canalejas (1910-1912) se vio vapuleado por la fuerte oposición del integrismo católico, al planear éste un decreto de regulación para la implantación de nuevas órdenes religiosas, que se verían restringidas durante dos años. «En 1913, -año de la muerte de nuestro protagonista- en una época de alternancia liberal y conservadora, se planteó la "Cuestión del catecismo", produciéndose una fuerte agitación política y popular, a favor y en contra, de la enseñanza de la religión católica en las escuelas.

\footnotetext{
7 AVILÉS, Juan: "Republicanismo, librepensamiento y revolución: la ideología de Francisco Ferrer y Guardia". En Ayer, n. ${ }^{\circ} 49$ (2003), pp. 249-270.

${ }^{8}$ DELGADO, Francisco: "El Sistema Educativo y su dependencia del Concordato de 1979". [en línea], [Consultado, 9 de octubre de 2020] Disponible en https:// laicismo.org/el-sistema-educativo-y-su-dependenciadel-concordato-de-1979/.
} 
El "Consejo de Instrucción Pública", teniendo en cuenta diversas opiniones, autorizó a los maestros que lo solicitaran no tener la obligación de enseñar el catecismo a aquellos niños cuyos padres así lo pidieran»?

En estos años de tensiones y enfrentamientos entre los clericales y los anticlericales transcurrió la vida de Colom Victor. Pero vamos a hacer una aproximación somera a cómo era el ambiente en la ciudad que le vio nacer y en la que pasó casi toda su vida. Sanlúcar de Barrameda, hasta mediados del siglo XVII, había vivido bajo un régimen feudal, pues estuvo bajo el señorío de los Medina Sidonia. Estos señores fundaron muchos conventos en Sanlúcar, cuyas iglesias aún subsisten. Hay que señalar, no obstante, que, tras las sucesivas desamortizaciones y exclaustraciones, el número de conventos y religiosos había descendido drásticamente en comparación con otras épocas. Pero a lo largo de la segunda mitad del siglo XIX se fueron implantando nuevas órdenes religiosas dedicadas a la enseñanza religiosa. Así que su influencia social seguía siendo notable, pues las femeninas se constituyeron también en lugares de retiro de damas viudas o solteras que, abrumadas ante el mundo, se alejaban del demonio y la carne. El clero secular, por otra parte, también siguió siendo numeroso, dada la inversión de recursos económicos que se realizó para dotar a la ciudad de un seminario católico con el patrimonio legado por don Francisco de Paula Rodríguez, que administraron los curas de la Parroquia Mayor. Y se incrementó el número de predicadores con la reapertura del convento de los capuchinos en 1877, por iniciativa, entre otros, del sanluqueño Andrés de Hoyos Limón, quien se integraría años después en el partido nacional tradicionalista fundado por Ramón Nocedal. Este convento aparece en diversas ocasiones como un auténtico refugio de tradicionalistas carlistas, realizándose en este sentido actos religiosos de un clarísimo sesgo político.

El protagonismo de la ciudad durante el breve período de la I República (1873-1874) y sus episodios anticlericales trajeron como consecuencia una represión política muy dura, que llevó a cientos de presos sanluqueños a la prisión y al destierro en las Islas Marianas ${ }^{10}$. Tardarían muchos años en recuperarse el republicanismo y el sindicalismo internacionalista en Sanlúcar tras esos crueles castigos. Paralelamente a esta recuperación, se fundaría el movimiento político integrista, abanderado por el poderosísimo conde Aldama, cacique local y diputado, que manejó los hilos del clericalismo local y aunó voluntades y recursos para

\footnotetext{
${ }^{9}$ Ibidem.

${ }^{10}$ ESPIGADO, Gloria: La primera República en Cádiz: estructura social y comportamiento político durante 1873. Sevilla, Jerez (Cádiz), Caja San Fernando, 1993.
} 
potenciar el poder jerárquico y autoritario de la iglesia católica y romana ${ }^{11}$. Todo ello de la mano de la influyente prensa católica de la época, como El Siglo futuro y otras cabeceras similares.

La instalación de la residencia veraniega de los Duques de Montpensier e Infantes de España, Antonio de Orleans y María Luisa Fernanda de Borbón favoreció la llegada a Sanlúcar de una pequeña corte de nobles, políticos y artistas, que le dieron a la ciudad una cierta fama como lugar de veraneo de la burguesía sevillana, además de la servidumbre propia de la corte borbónica monárquica. El periodo de la Restauración estuvo dominado por los problemas del subdesarrollo del campo andaluz y la pérdida definitiva de las colonias de ultramar tras el Desastre de 1898. A esta precariedad económica se le sumaba el problema del caciquismo, que hizo nacer en la zona un fuerte anarquismo, cuyo ejemplo más clásico a la par que discutido sería la Mano Negra. Desde finales del siglo XIX hasta principios del XX se construyeron varias líneas ferroviarias que unían Sanlúcar con lugares y ciudades en sus cercanías. En las primeras décadas del siglo XX, Sanlúcar se consolida como el más importante destino de veraneo del sur de España, esplendor turístico que contrasta con una situación social muy poco halagüeña.

\section{Antecedentes históricos y familiares}

José Colom Víctor nació en Sanlúcar de Barrameda en el seno de una familia burguesa y católica, de grandes dotes comerciales. Los Colom provenían de Cataluña y uno de sus más célebres miembros fue el vicario sanluqueño Rafael Colom Borrego (1762-1849). Fue una familia en la que no faltó ninguna profesión, cargo político o religioso importante ${ }^{12}$. Se trata sin duda de una de las familias sanluqueñas más importantes del siglo XIX y parte del siglo XX, en que ya vino a menos.

\footnotetext{
${ }^{11}$ Antonio de Aldama y Mendívil (1867-1930) fue diputado a Cortes por Guipúzcoa entre 1901 y 1903. Se destacó entre otras cuestiones por atacar duramente el matrimonio civil que los liberales trataban de aprobar. Militó en el catolicismo integrista con tal furor que en 1910 manifestó que estaba «dispuesto a derramar su sangre en defensa de la religión y la patria». Tras abandonar su primera profesión religiosa, se casó en 1899 con Dolores Pruaño y se avecindó en Sanlúcar de Barrameda. Tuvieron siete hijos, aunque fallecieron dos a corta edad. Los cinco restantes se consagraron a las profesiones religiosas, alcanzando cierta fama uno de ellos, José Antonio Aldama y Pruaño. Cuando sus hijos ingresaron en la vida religiosa, el matrimonio se separó y abrazó también la vida contemplativa, ordenándose Aldama como presbítero en 1929 dentro de la orden jesuita.

${ }^{12}$ Luis Gonzaga Colom Osorio, doctor en Teología; Merry Colom, escolapio. Otro, de igual apellido, embajador, además de escritor. Su hermano Luis Colom Víctor, fue nombrado vice-cónsul de Alemania en Sanlúcar de Barrameda, según consta en el "Diario de Avisos y noticias de Madrid", del 19 de abril de 1876. Al parecer hizo una carrera dentro del mundo diplomático. En su tumba del cementerio municipal de Sanlúcar se le califica como "Benemérito de la Patria". Falleció en 1929 con 81 años de edad. Blas Colom, depositario municipal, otro José Colom, regidor, etc. En cuanto al célebre vicario Rafael Colom, pueden leerse las páginas que le dedica CLIMENT BUZÓN, Narciso: Historia social de Sanlúcar de Barrameda, Sanlúcar, Aseha, 2009, T. 4 (en especial las pp. 522 y ss.).
} 
Como no podía ser de otra forma, fueron bodegueros y acumularon riquezas ya desde la invasión francesa, durante la cual surtieron de vinos y mercancías a las tropas invasoras. Posteriormente, cuando se lleva a cabo la desamortización de Mendizábal, Juan Nepomuceno Colom, un personaje político y empresarial de la época, compra conventos desamortizados para convertirlos en bodegas y aparece como dueño de una potente compañía mercantil ${ }^{13}$ y de cosecheros de vinos, además de ser el promotor de la primera Caja de Ahorros y Monte de Piedad creada en Sanlúcar ${ }^{14}$.

Nuestro hombre, José Colom Víctor, es hijo precisamente de Juan Nepomuceno Colom Ossorio (de Sanlúcar) y de María Teresa Víctor y Picó (de Cádiz) ${ }^{15}$. Nace en la casa de la calle Regina no 164 A, según la numeración antigua.

\section{Formación cultural, profesional e ideológica}

José Colom aparece como alumno matriculado en la Facultad de Farmacia de Madrid en el curso 1879-1880. Parece que ya es Licenciado en Medicina o matriculado en dicha carrera. Un año después, aparece matriculado para el sexenio 1881-1887 en la Facultad de Derecho de la Universidad Central, en la especialidad de Derecho Civil y Canónico. En 1887 registra también su matrícula para estudiar Derecho Mercantil, pero el 2 de abril pide el traslado de su expediente a la Universidad de Sevilla. Por la certificación académica oficial de la Facultad de Derecho se puede deducir que José Colom estudió el Bachiller y las asignaturas preparatorias de Derecho, desde el curso 1881-1882 hasta el curso 1885-1886 en la Universidad hispalense. Los simultaneó con un curso de Derecho Romano en Madrid, en 1882-83. Todas las asignaturas, excepto una de Derecho Civil, aparecen con la calificación de "aprobado", e incluso hay varias en las que aparece como repetidor (Historia Universal, Literatura griega y latina, Derecho romano y Derecho procesal). En marzo de 1883 había pedido también al rector de la Universidad Central el traslado de su matrícula en $2^{\circ}$ curso de Derecho Romano a la Universidad de Sevilla ${ }^{16}$.

\footnotetext{
13 ARCHIVO MUNICIPAL DE SANLÚCAR DE BARRAMEDA (AMSB), Actas capitulares: El 31 de diciembre de 1845 Juan Nepomuceno y Rafael Colom dan cuenta al Ayuntamiento de la formación de una compañía. En 1839, Nepomuceno figura como diputado por Sanlúcar en la Diputación Provincial de Cádiz (Guía de Cádiry su obispado, Cádiz, 1839).

${ }^{14}$ Hemeroteca digital de la BIBLIOTECA NACIONAL DE ESPAÑA (BNE): Diario La época, Madrid, 28 de septiembre de 1850.

15 María Teresa es hija de Liberato María Víctor Polloni y Dolores Picó Martínez. Tuvo cuatro hijos más, además de José: Teresa, Francisco, Luis y Juan. Falleció en 1884 con 68 años. Juan Nepomuceno Colom falleció el 23 de diciembre de 1876 con 76 años. Nació por tanto en 1800. Le llevaba pues 16 años de diferencia a su esposa. Esta era, según el leg. 5356 del ADMS, la presidenta de la "Sociedad de Señoras de San Vicente de Paúl" a la que el duque de Medina Sidonia contribuía con 280 reales cada dos meses.

${ }^{16}$ ARCHIVO HISTÓRICO NACIONAL (AHN): Universidades, Legs. 1035 (nº 78) y 3834 (nº 5).
} 
Así que nuestro hombre era médico y abogado, además de republicano militante y ateo confeso ${ }^{17}$. De sus años de Madrid parece que procede su relación con Fernando Lozano, escritor y periodista, fundador del semanario "Las Dominicales del Librepensamiento", que se publicó desde 1883 hasta $1909^{18}$. Su erudición le llevó a escribir un libro titulado "Cuadro sinóptico de la reconquista española”, impreso en Jerez en 1900 por M. Hurtado ${ }^{19}$. También, por lo que se deduce de su testamento, fue autor de diversos manuscritos de cuya publicación no existe constancia alguna: "Copia de las Actas Capitulares del Ayuntamiento de Sanlúcar, 1787-1897", "Clasificación de la Biblia y Evangelios" y "Prólogo". En Sanlúcar, Colom se relaciona con personajes como Eduardo Gutiérrez Enríquez, demócrata y republicano, director de periódicos locales e incluso músico, que aparece también como uno de los militantes del partido de Estanislao Figueras y del Librepensamiento, al estar suscrito también a "Las dominicales..." de Fernando Lozano. Eduardo Gutiérrez fue diputado provincial y uno de los más activos concejales durante la breve experiencia cantonal revolucionaria. Parece que tuvo que exiliarse en París después de 1873, donde estuvo acompañando al líder nacional Ruiz Zorrilla ${ }^{20}$. Gutiérrez fue incluso encarcelado en 1884 en su condición de director del diario "La Crónica Local" a causa de una denuncia presentada por el Ayuntamiento ${ }^{21}$. También, a través de su común militancia republicana mantiene contactos con intelectuales de la talla de Vicente Blasco Ibáñez, a quien atiende en una visita del novelista a Sanlúcar en el verano de $1904^{22}$.

Todo ello no obsta para que Colom Víctor se apunte como colaborador económico de los gastos producidos por la "Guerra de Cuba", pues en el diario católico El Siglo Futuro aparece como uno de los contribuyentes sanluqueños (en la relación correspondiente a la clase médico-farmacéntica) a la suscripción nacional con motivo de la Guerra de 1898, a la que donó 250 pesetas, siendo de los más generosos, pues la mayoría entregó 100 pesetas o $\operatorname{menos}^{23}$.

\footnotetext{
${ }^{17}$ En la Guía Oficial de Cádizy y su Provincia para 1906, José Colom aparece como uno de los 12 abogados en ejercicio existentes en Sanlúcar.

18 Sobre el Librepensamiento y Lozano se pueden consultar las interesantes páginas de HUERTAS VÁZQUEZ, Eduardo: “El grupo Germinal y el Librepensamiento español”. En ÁLVAREZ LAZO, Pedro (Ed.): Librepensamiento y secularización en la Europa contemporánea, Universidad Pontificia Comillas, Madrid, 1996, p. 265296. En cuanto a la biografía de Lozano Montes, se puede consultar en: http://www.filosofia.org/ave/001/a340.htm

${ }^{19}$ Hay un ejemplar existente en la Biblioteca Nacional, con su firma autógrafa, con signatura 1/18469.

${ }^{20}$ DAZA PALACIOS, S.: "La persecución del periodista republicano Eduardo Gutiérrez". Art. Inédito.

${ }^{21}$ BIBLIOTECA NACIONAL DE ESPAÑA (BNE): Hemeroteca digital, El Día, Madrid, 5 de diciembre de 1884. (Disponible en http:/ / hemerotecadigital.bne.es/issue.vm?id=0002183246\&search=\&lang=es )

22 El Guadalete, 22 de julio de 1904.

23 BNE: Hemeroteca digital, El Siglo Futuro, Madrid, 3 de mayo de 1898. (Disponible en http:/ / hemerotecadigital.bne.es/issue.vm?id=0000197948\&search=\&lang=es)
} 
El escritor y periodista José Antonio Caballero, que le conoció personalmente, le describió como un auténtico erudito ${ }^{24}$ : Abogado, médico, bibliófilo, propietario, caballeroso, algo excéntrico, amigo de la forma de gobierno republicana. Uno de esos hombres que pasan por la vida consagrados al estudio sin alharacas. El retrato de Colom es muy preciso, pues le dibuja como una persona independiente y sabia:

Ha sabido hermanar la modestia con el talento y baciendo labor de hormiguita, se licenció en dos Facultades, sobrándole aún tiempo para cuidar de su pingüe caudal, que administrar sabe como el más depurado comerciante. El sólo hecho de ser rico en bienes y dedicar al estudio las primicias de su clara inteligencia, motivo es para que le presentemos como modelo de bombres aptos y beneficiosos a la sociedad, desgraciadamente, muy necesitados de ellos.

La extraña y particular inclinación de Colom por el estudio se hace notar entre una sociedad que cultiva «otros vicios»:

... no deja pasar día sin dedicar al estudio tiempo suficiente para cultivar su inteligencia, ya en materia tan complejas y varias como son la Medicina y el Derecho, ya en sus trabajos bibliófilos a los que dedica preferente atención. Metódico y ordenado como el más depurado sibarita, le veréis con puntualidad de horario distribuir el tiempo, que es virtud grande, en cosa que parece tan nimia; asi que a pesar de sus aficiones y trabajos varios no deja pasar un día de practicar el masaje intelectual tan necesario para el cultivo de las inteligencias.

Entre las cualidades de José Colom brillaban la modestia y la falta de ambición, pues no había logrado cargos o puestos acordes con su talento y preparación:

Si los pueblos se gobernaran por ciudadanos del temple de pazy de orden que naturalizan a don José Colom y Victor, otra cosa sería la administración y la justicia. (..) Médico, abogado, propietario capitalista, noble y caballero, son gloriosos timbres que le adornan de nobleza y honradez, (..) que son galas del hombre que, como premio a sus virtudes y cualidades, recibe los aplausos, no buscados, de la opinión, pasando a la posteridad con un renombre adquirido por derecho propio y en el que se vincula el de toda una familia.

\section{Presidente honorario de los republicanos}

A finales del siglo XIX, el Partido Republicano en Sanlúcar se había podido recomponer totalmente y su secretario general era Miguel Ruiz Duque. En 1902 existía además el Casino Republicano, que confirmó su adhesión, propuesta por su presidente, Diego Gallegos, al Comité Nacional Librepensador, según telegrama enviado por su

${ }^{24}$ CABALLERO, José Antonio: Siluetas sanluqueñas., Tipografía Doménech, Sanlúcar de Barrameda, 1900. 
vicepresidente, Manuel Álvarez Padilla, a Las dominicales del libre pensamiento ${ }^{25}$. El comentario del rotativo es el siguiente: «Eso está muy en consonancia con el empuje libertador que palpita en el proletariado sanluqueño, y será celebrado por el librepensamiento internacionals.

Bajo esta impronta ideológica, no resulta extraño que el Partido Republicano sanluqueño nombrara como presidente de honor a Colom Víctor, junto, nada menos, que a Nicolás Salmerón y a José Marenco Gualter, que había sido diputado republicano por Cádiz en 1893.

Se celebraron mítines de propaganda en cada uno de los cinco distritos de la ciudad y tras ellos se constituyeron las cinco juntas de distrito y se eligió el comité municipal del republicanismo local. La presidencia efectiva la ostentaría el citado Diego Gallegos Vázquez, acompañándole como vicepresidentes Joaquín Gordillo Guzmán y Manuel Álvarez Padilla. Los secretarios sería Andrés Romero Ibáñez y Benito Gómez Vinuesa ${ }^{26}$.

Como uno de los herederos del célebre vicario Rafael Colom, José Colom Víctor aparece también en 1895 enfrascado en diversos trámites para solicitar al ministro de Hacienda una certificación relativa a la capellanía fundada por Beatriz de Olivares ${ }^{27}$. Explica en su solicitud que «en 1842 se adjudicó a Rafael Colom y Borrego, como más próximo pariente, la capellanía de doña Beatriz de Olivares, gravada con cien reales al año». Y explica al ministro «que el Estado debió oponerse a esta concesión» pues él tenía conocimiento de que la Junta Superior de Bienes Nacionales declaró que dicha capellanía pertenecía a la clase de familiares ${ }^{28}$.

\section{Su disidencia religiosa: creación de un cementerio civil en Sanlúcar}

Pero aun a pesar de estas peticiones que tenían su origen en los privilegios eclesiásticos, José Colom era bien conocido en su época por su radical disidencia religiosa. Y una de las cuestiones por las que luchó más fue por la creación de un cementerio civil donde

25 BNE: Hemeroteca digital, Las dominicales, edición del 14 de noviembre de 1902, (disponible en http:/ / hemerotecadigital.bne.es/issue.vm?id=0000197948\&search=\&lang=es)

26 BNE: Hemeroteca digital, El País (Madrid), edición del martes 27 de octubre de 1903, (disponible en http:/ hemerotecadigital.bne.es/issue.vm?id=0001981273\&search=\&lang=es). Le siguen otros muchos ciudadanos como vocales.

27 ARCHIVO HISTÓRICO NACIONAL (AHN): Fondos contemporáneos del Ministerio de Hacienda, leg. 5842, exp. 63.

${ }^{28}$ Las capellanías eran obras pías instauradas en la Iglesia Católica, mediante las cuales el fundador, generalmente una persona acaudalada, dejaba en su testamento una cantidad de dinero que se ponía en renta, para que con las ganancias se pagara la realización de un número determinado de misas por la salvación de su alma. Algunas de estas ganancias provenían de los "censos" que gravaban determinadas propiedades urbanas o rústicas y que servían para mantener al capellán encargado de decir las misas. Las capellanías familiares eran aquellas llamadas también "de sangre o parentesco". Se debían conferir con arreglo a las cláusulas de su fundación a parientes y miembros del linaje fundador. CANDAU CHACÓN, María Luisa: La carrera eclesiástica en el siglo XVIII, Sevilla, Universidad, 1993, p. 391. 
pudieran enterrarse los no creyentes. Un suelo funerario ajeno a cualquier tipo de servidumbre religiosa.

La cuestión arrancaba de lejos, pues por una Ley de abril de 1855, el Gobierno de Isabel II ordenó la construcción de cementerios especiales para los no católicos en aquellas poblaciones en las que a juicio del Gobierno lo exigiera la necesidad. Posteriormente, por una Real Orden de febrero de 1872 se reguló la construcción de cementerios para los no católicos. La adquisición de los terrenos por los Ayuntamientos, «para la construcción de un cementerio o ampliación del existente, y de las obras necesarias, gozaría de la declaración de utilidad pública». Otra Real Orden de mayo de 1882 prescribió que, para la inhumación de los cadáveres de los no católicos, se debía construir otro camposanto, anejo al cementerio católico, con arreglo a las dos Leyes antes mencionadas, porque la mayoría de los Ayuntamientos no había cumplido lo preceptuado en 1872. Nuevamente, en una Real Orden de abril de 1883 se obligó a las corporaciones locales de poblaciones de más de 600 vecinos a construir un nuevo cementerio con ese fin o a ampliar el ya existente ${ }^{29}$.

En Sanlúcar, los años fueron pasando y ninguna lumbrera municipal se dio la más mínima prisa por cumplir tan repetidos decretos reales. Así que tuvo que ser José Colom quien recordara a los ediles sanluqueños la obligación que tenía el municipio de dar satisfacción a quienes no querían ser enterrados en tierra católica. En una sesión de la Comisión de Fomento del Ayuntamiento, celebrada el 24 de julio de 1909, se analizó la propuesta presentada por Colom para que se construyera un cementerio civil «en condiciones de decoro, para sepultar a los que no profesen religión alguna». Este asunto se había llevado a la sesión del Ayuntamiento del 12 de mayo anterior pero no se había decidido nada hasta que no se pronunciase la Comisión de Fomento. Esta comisión estaba presidida por el propio alcalde Leopoldo del Prado (conservador) y otros concejales más, y su dictamen fue el siguiente:

"Después de un maduro examen, tienen que dictaminar que esta pretensión, en la forma formulada, no es admisible en modo alguno. Ahora bien, como la creación de un cementerio Municipal Católico que sustituya al actual, falto de condiciones higiénicas, es un problema que antes de abora ha abordado este Ayuntamiento, parece que, con la ejecución de ese proyecto, dentro del que cabe la existencia [del] que puede llamarse Civil, quedarán (sic) de paso llenado el objetivo que persigue el Sr. Colom 30».

\footnotetext{
${ }^{29}$ FERNÁNDEZ HIDALGO, Ma del Carmen / GARCÍA RUIPÉREZ, Mariano: "Los cementerios. Competencias municipales y producción documental", En Boletín de ANABAD, T. 44, nº 3, 1994, pp.55-85. JIMÉNEZ LOZANO, José: Los cementerios civiles y la beterodoxia española., Barcelona, 2008.

${ }^{30}$ ARCHIVO MUNICIPAL DE SANLÚCAR DE BARRAMEDA (AMSB): Actas de Fomento, leg. 1254.
} 
El cementerio "civil" de Sanlúcar consistió finalmente en un pequeño espacio añadido al cementerio católico de san Antonio Abad, aunque separado e incomunicado con este, y en cuyos nichos se enterraban quienes no profesaban ninguna religión o profesaban otras distintas de la católica oficial, así como los suicidas y demás difuntos sin familiares. Esta almacabra o corraleta (pues no podía siquiera calificarse como tal cementerio) sirvió también como fosa común donde fueron enterrados los fusilados por los franquistas durante el principio de la Guerra Civil. Este enterramiento desapareció en los años 80 del pasado siglo, pues su espacio fue absorbido por el cementerio católico.

\section{Fallecimiento y entierro civil}

Ante la muerte de nuestro protagonista a fines de 1913, el diario local El Profeta, se dejó caer con el siguiente comentario barroco y malévolo ${ }^{31}$ :

Ha muerto: pasó por la vida en constantes pugilatos defensivos de finalidades religiosas desafectas al medio ambiente de la sociedad en que vivía. Este aislamiento de compenetración doctrinal de ultratumba, que bubiera desanimado a cualquiera, a don José Colom Victor le sirvió tal vez de acicate para la perseverancia; $y$ abroquela (sic) de sus extraños ideales, ha bajado a la fosa.

El Ayuntamiento, por el contrario, acordó que constase en acta el sentimiento de la corporación «por el fallecimiento del preclaro bijo y Jefe del Partido republicano...y que se nombrase una comisión que diese el pésame a la familia y acompañase al duelo» ${ }^{32}$. Su entierro, por tanto, constituiría un evento oficial en el que se dieron cita muchas personas de relevancia en la ciudad.

En el certificado de defunción ${ }^{33}$, registrado a las dos de la tarde del día 13 de diciembre de 1913 ante el juez municipal Manuel de Soto Díaz y el secretario judicial Manuel de Diego Briñoles, compareció Manuel Artárida Infante, casado y empleado, «manifestando que don José Colom y Víctor, propietario, natural de esta ciudad, de edad cincuenta y nueve años, domiciliado en la calle de González Hontoria número 1, falleció a las diecinueve y quince del día once, en su referido domicilio, a consecuencia de carcinoma intestinal, de lo cual daba parte en debida forma como encargado por la familia. El referido finado era soltero. Era hijo de D. Juan y de $\mathrm{D}^{a}$ María Teresa y tiene otorgado testamento».

\footnotetext{
31 AMSB: Diario El Profeta, Sanlúcar, 14 de diciembre de 1913.

32 AMSB: Actas capitulares de 1913, en el punto $6^{\circ}$ de su sesión del 12 de diciembre.

${ }^{33}$ Registro Civil de Sanlúcar de Barrameda: n 576, correspondiente al 13 de diciembre de 1913.
} 
Se deja claro en el documento que a «su cadáver se le ha de dar sepultura en el cementerio de disidentes de esta ciudad» y no en el católico de san Antonio Abad, por expreso deseo manifestado por el finado antes de morir. Todo lo cual lo presenciaron como testigos Juan Velázquez Ortiz, casado, empleado y Juan Hermoso Reyes, casado, industrial.

Su entierro, al día siguiente, causó un gran escándalo entre los integristas católicos y una ardua polémica periodística. El mismo día del entierro, desde Sanlúcar, el conde de Aldama envía una protesta por medio de un telefonema a su amigo el director del diario católico El Siglo Futuro, Manuel Senante, diputado conservador e integrista. Al no encontrarse en Madrid, el comunicado no se publicó hasta una semana más tarde en la portada del rotativo:

Sanlúcar: Con escándalo de esta católica ciudad, han asistido boy a un entierro civil el alcalde, el juez municipal y gran número de conservadores. Los católicos, indignados, protestan contra esta manifestación antirreligiosa, y piden al ministro de la Gobernación y al de Gracia y Justicia que apliquen la sanción legal a dichas autoridades. - Aldama.

A raíz de esta información, El Siglo Futuro pone el grito en el cielo y se une a la protesta de tan acendrado personaje:

"Ciertamente, la legalidad establecida no permite que la "tolerancia" se convierta de becho en "libertad". Los entierros civiles, o son una manifestación de culto disidente, o contra la religión del Estado, que es la católica. Y es bien sabido — pues asi lo dispone la Constitución - que no se permitirán otras manifestaciones religiosas públicas que las de la religión del Estado.

El diario integrista alegaba que estaba prevenido que los entierros civiles se verificaran sin ostentación. Y que el cortejo fúnebre pasara por la vía más corta hacia el cementerio, alejándose de las calles céntricas de la población. Por tanto, calificaban el entierro de «manifestación ilegal»:

La protesta de los católicos de Sanlúcar — a la que unimos la nuestra - está muy en su lugar, y la petición de que se exijan las responsabilidades debidas, es justísima y conforme a derecho, porque las leyes se hacen para cumplirlas, $y$, mientras no se deroguen por otras, obligan a todos, pero más principalmente a los que, investidos de alguna autoridad, tienen el deber de hacerlas cumplir. Del escandaloso hecho que se nos denuncia, notificamos a los señores ministros de la Gobernación y de Gracia y Justicia, para que restablezcan el imperio de la ley y no quede impune la ofensa recibida por los católicos» ${ }^{34}$.

34 BNE: Hemeroteca digital, El Siglo Futuro, Madrid, 20 de diciembre de 1913, (disponible en http:/ / hemerotecadigital.bne.es $/$ issue.vm?id=0000317601\&search=\&lang=es) 
Un alegato tan integrista y ultramontano no podía quedar sin respuesta. Así que dos días después le replicó el diario republicano El País con un suelto en su primera plana, titulado "Qué brutos!”. Manifestaba el rotativo madrileño que no conocía esa ley que castigaba la asistencia a los entierros civiles. Y recordaba los anteriores sepelios de Pi y Margall, Benot, Pi y Arsuaga, Salmerón, Torre Murillo, y otros, a los que asistieron personajes católicos. Pero no «de tres al cuarto, sino ministros, magistrados del Supremo, presidente de las Cortes, alcaldes, generales, etc. Al de Pi y Margall asistieron ministros conservadores y algún diputado carlista. Al de Salmerón quiso Maura, presidente del Gobierno, revestirlo de honores oficiales. No había por tanto que tomar en serio la denuncia integrista, sino tomársela a chanza, pues era producto de que sus denunciantes habían bebido «el vinillo integrista, que es desagradable en todas partes, pero es vinagre en Sanlúcan ${ }^{35}$.

El diario católico reaccionó y replicó dos días más tarde insistiendo en sus posiciones ortodoxas sobre tan «motivada y justísima protesta»:

Los "recuerdos" que hace El País, si no sirven para justificar el atropello al derecho de los católicos, la ofensa grave inferida a los sentimientos religiosos católicos de todo un pueblo amparados por la legalidad establecida, sirven para que se vea a buena luz lo que es el liberalismo prácticamente, el radical y el moderado. Y esto dicho, recordemos, a nuestra ver, que está clarísimo y terminante el artículo 11 de la vigente Constitución en declarar que la Religión Católica, Apostólica, Romana, es la del Estado, y no se permitirán otras ceremonias y manifestaciones que las de la Religión católica. No menos clarísimo y terminante es lo prevenido en la Real Orden de 23 de Octubre, prohibiendo toda manifestación de cultos o sectas disidentes fuera del templo o del cementerio no católicos.

El diario ultra no podía admitir bajo ningún concepto que al fallecer un disidente se levantase en público una bandera de secta, escuela o partido heterodoxo, atropellando la ley constitucional, pues se pretendía así convertir la mera tolerancia religiosa en una facultad o derecho de libertad religiosa, haciendo público alarde de disidencia católica:

Lo vigente es que los entierros civiles, cuando puedan verificarse, se realicen sin pompa, sin carácter de manifestación pública, sin ostentación de la creencia o culto disidente, sin ruidos de músicas ni discursos o elogios fúnebres. Así lo dispone la Real Orden de 22 de abril de 1857 en concordancia con el art. 11 de la Constitución y la Real Orden de 23 de octubre de 1876, en lo que a entierros civiles se refiere, no invalidada por la reciente disposición aclaratoria que tuvo la debilidad de dictar el infortunado Sr. Canalejas ${ }^{36}$.

35 BNE: Hemeroteca digital, El País, Madrid, 22 de diciembre de 1913, (disponible en http:/ / hemerotecadigital.bne.es/issue.vm?id=0002454757\&search=\&lang=es). Este comentario enólogico viene quizás a cuento en referencia a que el citado conde Aldama, líder del integrismo local, era un conocido vinatero. ${ }^{36}$ José Canalejas (1854-1912) fue nombrado presidente del Consejo de Ministros en febrero de 1910 y desató las iras de los integristas católicos al promover diferentes medidas anticlericales, tales como, precisamente, una Real Orden de 10 de junio de 1910 firmada por el rey que autorizaba «los letreros, banderas, emblemas, anuncios, carteles y demás signos exteriores que den a conocer los edificios, ceremonias, ritos, usos o costumbres de cultos distintos del de la religión del Estado». Cabe recordar que Canalejas fue asesinado el 12 de noviembre de 1912 en la Puerta del Sol por el anarquista Manuel Pardiñas. 
Y también recuerda que el gobernador civil de Baleares había dictado una instrucción el 2 de octubre de 1900 por la que se ordenaba el procedimiento a utilizar para los enterramientos de quienes murieran fuera de la religión católica, para evitar que estos entierros civiles se convirtieran «en manifestación pública de hostilidad a la Religión del Estado». El diario ultracatólico termina preguntando:

¿Se procedió ahora así en Sanlúcar de Barrameda? ¿No? iPues entonces, harto justificada está la protesta que tanto ha excitado las iras de El País!

\section{Su testamento}

Está claro que, con estos mimbres, la cuestión del testamento ológrafo dejado por Colom Víctor a su muerte traería cola. Mucha cola. No se trataba de un personaje cualquiera sino de una persona muy compleja, sin descendencia directa, sin esposa, pero sobrado de bienes, la mayor parte de ellos recibidos por herencia de sus familiares. José Colom dejó encargado a varias personas de su confianza que una vez ocurriera su fallecimiento recogiesen el testamento de su casa y lo presentasen ante el juzgado y la notaría correspondiente para protocolizarlo debidamente, sin cuyo trámite no tendría valor ninguno ${ }^{37}$. Sus grandes conocimientos del Derecho y su militancia ideológica hacían presagiar un documento de últimas voluntades muy especial.

El testamento había sido redactado el 8 de abril de 1913, nueve meses antes de su fallecimiento. El notario José Luis Fernández Terán lo protocolizó el 27 de diciembre del mismo año. En la cláusula primera de su testamento, Colom Víctor dejaba bien claro, haciéndolo constar «enérgicamente», que no profesaba «ninguna religión». Ordenaba que su cadáver, a falta de cremación, sea embalsamado, colocado en una caja de plomo y otra de madera, y que la conducción del mismo al sitio de la sepultura y esta, sean completamente civil.

Instituyó como heredera usufructuaria a una señora sanluqueña que se sospecha podría haber sido su asistenta o ama de llaves. Colom le deja una gran porción de bienes, fincas rústicas e inmuebles de un gran valor económico, situados en el casco histórico de la ciudad, pero ninguno de ellos podría ser vendido, pues la heredera sólo disfrutaría de sus rentas mientras viviese, y a su muerte, todos los bienes pasarían a disfrutarlo en usufructo sus cinco sobrinos carnales, Elena, Luisa, Juan Antonio, José Martínez, Colom y José Colom Matheos.

${ }^{37}$ ARCHIVO HISTÓRICO PROVINCIAL DE CÁDIZ (AHPC): Protocolos de Sanlícar de Barrameda. Notaría de José Luis Fernández Terán, Año 1913, leg. 8388, ff. 893 y ss. Esta copia original ha sido contrastada con la inscripción y traslación que consta en el Registro de la Propiedad, Año 1915, Tomo 454, Libro 258. 
A estos mismos sobrinos deja en el testamento sus alhajas, valores, mobiliarios, cuadros, muebles y demás bienes que poseía, y que podrían repartir por partes iguales. También otorgó una pensión vitalicia de diez reales diarios para alimentos al joven José Galán Ibáñez, hijo de José y de Carmen, que convivía con él en la misma casa. Y ordenó que se mantuviera la pensión de 750 pesetas anuales que ya aportaba a otra sobrina suya llamada María Teresa.

Pero ninguna herencia recibirían estos sobrinos si no se cumplía su condición y deseo de ser enterrado civilmente. Si este propósito no se llevaba a cabo, todos los bienes pasarían a usufructo de su amigo Fernando Lozano, director del periódico librepensador "Las Dominicales" y si éste bubiese fallecido, a sus más próximos parientes naturales ${ }^{38}$. Su firme convicción en este sentido hizo que ordenara el traslado de su cadáver al cementerio civil de Jerez de la Frontera si para la fecha de su fallecimiento el Ayuntamiento de Sanlúcar no hubiera aún construido uno, tal y como tenía solicitado y estaba obligado por la Ley. Este traslado a Jerez se haría en el caso de que la Iglesia no permitiese que se pudiera enterrar en el «cementerio para disidentes» que se mantenía adosado al cementerio católico.

A este respecto también deja ordenado que ninguno de sus herederos pudiera introducir ningún difunto en alguno de los dos nichos en los que yacían los cadáveres de sus padres en el cementerio católico -y que había comprado en propiedad y a perpetuidad en 1888-, «pues únicamente han de estar en ellos los de mis queridos padres» ${ }^{39}$.

\footnotetext{
${ }^{38}$ Fernando Lozano Montes (1844-1935) También conocido por "Demófilo", fue militar, periodista, masón, anticlerical, republicano y activista del librepensamiento, cofundador con Ramón Chíes del periódico "Las dominicales". Falleció con 91 años y fue enterrado en el cementerio civil. Cuando falleció fue considerado como el primer apóstol de la República; tuvo la satisfacción de haber visto proclamar la Segunda el 14 de abril de 1931, aunque muchos ya le habían dado la espalda y le habían olvidado. Estudió Filosofía y Derecho en la Universidad Central. Cuando tomó posesión de la monarquía Amadeo I, Lozano, en su condición de militar de carrera, se negó a jurar al nuevo rey, por lo que tuvo que abandonar el ejército, aunque volvió cuando triunfó la Primera República en 1873, ejerciendo como profesor de la Academia de Administración Militar. En este puesto siguió tras la restauración monárquica de 1876, aunque parece que dos años después lo dejó y abrió una Academia privada en Madrid. Su nombre comenzó a hacerse conocido en la prensa, en combativos artículos en los que destilaba su ardor anticlerical. En 1885 forma, junto con Chíes y Pí Margall, el trío de albaceas testamentarios que Felipe Nieto Benito, militar republicano federal nacido en Guadalajara, dispuso para que fuera creada, una vez fallecida su hermana, la Escuela Laica de Guadalajara, que sería abierta en 1902, bajo la tutela de Lozano, escuela pionera en su género en España y que mantuvo vínculos con la Escuela Moderna que Francisco Ferrer Guardia tenía en Barcelona. El activismo librepensador le llevó al abandono de la carrera militar, dedicándose por completo al periodismo y el agitprop, de la mano de la masonería. (Información extraída de http://www.filosofia.org/ave/ 001/a340.htm Web consultada el 19/01/2020) Lozano estuvo en contacto con los republicanos sanluqueños, como puede comprobarse con la crónica publicada el 15 de agosto de 1902 en Las dominicales..., en la que el propio Lozano relata en primera persona su estancia en Sanlúcar y su intervención en un mitin.

${ }^{39}$ Esta parte se cumplió relativamente; pues, a día de hoy, en el cementerio católico de Sanlúcar existe un nicho conjunto para el matrimonio Colom y Víctor, dándose la circunstancia de que en el otro está enterrado un hermano de José, Luis, fallecido en 1929 y sepultado justo debajo de sus padres, cosa que, evidentemente, no pudo ocurrir con José. (Visita efectuada el 2 de noviembre de 2010, con el testimonio de una fotografía hecha por el autor de este artículo).
} 
Todas las cláusulas de esta complicadísima última voluntad presentan dificultades. Parece como si el testador hubiera querido lanzar un reto a sus herederos para que superaran sus prejuicios y renunciaran a sus creencias si verdaderamente querían disfrutar de unos sustanciosos bienes. La cláusula decimotercera, por ejemplo, ordenaba que ninguno de sus herederos pudieran tomar posesión de estos bienes sin haber hecho antes una impresión de al menos cincuenta ejemplares de cada una de las obras manuscritas que dejó terminadas. Las ya citadas "Copia de las Actas del Ayuntamiento de Sanlúcar de Barrameda desde el año de 1787 al 1897”, que estaban contenidas en unos mil quinientos pliegos; un trabajo sobre la Clasificación de la Bibliay Evangelios, que contaba con unos cuatrocientos pliegos; y otra obra titulada Prólogo, que sumaba unos dieciocho folios. Y para asegurarse de que esta cláusula se cumplía debidamente, dejaba ordenado que ningún usufructuario pudiera «tomar posesión del usufructo sin [antes] presentar copia de escritura pública en la que el notario otorgante copie esta cláusula, y dé fe de haber visto el número de ejemplares de cada una de las tres obrass ${ }^{40}$.

\section{La Fundación Laica}

Pero, sin ninguna duda, era la cláusula decimoquinta la más peculiar y la más chocante para el espíritu conservador de la época. Hay que tener en cuenta que Colom Víctor vivió en una época muy convulsa desde el punto de vista del enfrentamiento ideológico, pues el catolicismo se había hecho muy fuerte tras la restauración borbónica y no estaba dispuesto a ceder un ápice en sus privilegios y principios tradicionales. Es la época en la que las escuelas laicas de Ferrer Guardia tratan de hacerse un hueco en el monopolio que hasta entonces tenía la religión católica en la educación pública.

Así, Colom, que sin duda era seguidor de esta "Escuela Moderna”, dejó mandado en dicha cláusula que, una vez fallecido el último de los usufructuarios de su herencia, todos los bienes inmuebles rústicos y urbanos y derechos reales que tuviera en el momento de su fallecimiento y que constituían tales usufructos, deberían «pasar a servir para que con sus rentas exista en Sanlúcar una Cátedra en donde se haga saber que todas las religiones son falsas, a cuyo fin con todos los dichos bienes inmuebles y derechos reales [se] constituya una Fundación perpetua al efecto».

La minuciosidad con la que Colom redactó su testamento se comprueba en que contempló incluso las normas por las que se debería regir tal Fundación y quienes deberían ser sus patronos: En primer lugar, debería integrarse en ella «la Asociación de Libre Pensadores,

40 Por más que hemos indagado no hemos podido localizar la prueba de que, en efecto, estas obras se imprimieron. Si así fue, no ha quedado testimonio alguno de ello que hayamos podido encontrar. 
partidarios de la desaparición de todas las religiones, que exista en esta ciudad. A su falta o renuncia, la que bubiese en la ciudad, pueblo o villa de España más próxima a ella en línea recta. Y, en su defecto, y por el mismo orden de distancia, la de la nación francesa de Europa; y por falta de ésta la de otras naciones, según va dicho, por proximidad». Pero esta asociación, que sería el primer patrono de la nueva Fundación, debería estar integrada «lo menos por siete varones mayores de 23 años que existan en esta ciudad y que no hayan sido bautizados por la Iglesia Católica y que en su vida no bayan ejecutado acto alguno perteneciente ni al dogma ni al culto de ninguna religión».

El segundo miembro de la Fundación sería cualquier pariente suyo que lo solicitase, «prefiriendo el varón a la hembra y el de más edad al de menos». Pero si hubiese algún pariente que no profesase religión alguna sería este el que debía ejercer el patronato.

Un tercer miembro de la Fundación Laica sería la Junta Directiva del Partido Republicano existente en Sanlúcar. Este partido debía ser necesariamente partidario del sufragio universal. Si no hubiese ningún partido de estas características en la población o el que hubiera renunciase a pertenecer a la Fundación, se debería integrar en ella el partido «de la población más cerca a ella que quiera; y si lo solicitase más de una de las Juntas directivas que existan en una localidad, se le dará a aquella que sea más antigua».

El cuarto y último patrono sería el catedrático de Filosofía de la Universidad de Sevilla. Pero si rechazase pertenecer a esta Fundación, se le ofrecería «al de la Universidad que sea más próxima a esta ciudad».

\section{Problemas con la herencia: Informe del Ministerio de Instrucción y Bellas Artes}

La tramitación de tan compleja herencia trajo consigo toda clase de dificultades. Se inmiscuyó en el asunto el gobernador civil de Cádiz, como presidente de la Junta Provincial de Beneficencia. Se puso en contacto con el Ministerio correspondiente para tratar de capturar los bienes de Colom para un fin "decente". De ello se hicieron eco en su momento varios medios periodísticos entre los que no podía faltar el diario ultra madrileño El Siglo Futuro $^{41}$. El dictamen dado por el Ministerio se publicó como Real Orden el 10 de abril de 1916 y se publicó en la Gaceta del día 26, «disponiendo que hasta tanto se extingan los usufructos instituidos en su testamento por don José Colom, no es procedente que la Administración incoe expediente de clasificación ni resuelva acerca de la Fundación creada por dicho señor en Sanlúcar de Barrameda».

41 También por el diario El Globo (BNE: Hemeroteca digital, El Globo, 26 de abril de 1916, (disponible en http://hemerotecadigital.bne.es/issue.vm?id=0001419571\&search=\&lang=es)) y por supuesto la Gaceta de Instrucción Pública y Bellas Artes, (BNE: Hemeroteca digital, Gaceta de Instrucción Pública y Bellas Artes miércoles 3 de mayo de 1916, (disponible en http://hemerotecadigital.bne.es/issue.vm?id=0003437714\&search=\&lang=es) 
Este dictamen sobre la herencia de José Colom y sus intenciones de crear una Fundación laica, realizado a instancias del gobernador y presidente de la Beneficencia de Cádiz, puso de momento las cosas en su sitio y paralizó cualquier intento de apropiación por parte del Estado de los bienes del librepensador sanluqueño.

La Junta Provincial de Beneficencia gaditana se había dirigido el 1 de agosto de 1914 al Ministerio para informarle que había fallecido Colom a fines del año anterior, «bajo un testamento que establecía una fundación con carácter benéfico-docente». Se comprobó entonces «la imposibilidad legal de que pudiera ser autorizada, admitida ni clasificada, «por resultar manifiestamente contraria a la moral y a las leyes, y llevar en si un vicio patente de nulidad, presumiendo sería probibida». Se explicaba que el testador rogaba con encarecimiento «que se sostuviera con vigor una Cátedra para dar a conocer la verdad y en contra de todas las religiones, manantiales de falsedad e ignorancia que conducen a la esclavitud de los hombres».

Unos años después, una vez proclamada la Segunda República, el izquierdista Ayuntamiento de Sanlúcar propuso premiar a los republicanos "históricos" de la ciudad mediante la nominación de calles que recordaran su nombre al pueblo y a la sociedad futura. Así, dentro de la nómina de estas calles dedicadas a figuras políticas e intelectuales progresistas, se recoge la denominación, aprobada en la sesión del 21 de octubre de 1932, del "PASEO de DON JOSE COLOM VÍCTOR", que no era otro que la actual Calzada de la INFANTA. Curiosamente, la calle donde vivió, Regina, pasó a denominarse Francisco “FERRER y GUARDIA", el promotor de las Escuelas Laicas.

\section{Intento del Ayuntamiento republicano para rescatar la Fundación}

A raíz de la reivindicación de la figura política de Colom que representaba la dedicatoria de uno de los paseos más importantes de la ciudad, los concejales izquierdistas de Sanlúcar, Chamorro y Ruiz, propusieron también, mediante una moción, que el Ayuntamiento abanderase la creación de la Fundación propuesta por Colom Víctor ${ }^{42}$. La moción se deja llevar más por informaciones orales que por lo reflejado documentalmente en el testamento, aunque evidentemente su presentación lleva una gran intención política. El texto es el siguiente ${ }^{43}$ :

\footnotetext{
42 AMSB: Carpeta de la Asesoría Jurídica. Año 1934. Moción de los concejales Chamorro y Ruiz, fechada en Sanlúcar, el 11 de septiembre de 1934.

${ }^{43}$ Hemos destacado en cursiva aquellas ideas que están deformadas con respecto al texto original del testamento.
} 
«El día 11 de diciembre de 1913 falleció en esta Ciudad, donde había nacido en 17 de diciembre de 1854, don José Colom y Víctor, el cual en el objeto de propagar los ideales que siempre profesó, donó su fortuna a esta población con el fin de que con las rentas de la misma fuese creada y sostenida una Escuela en la que hubiese una cátedra dedicada únicamente $a$ enseñary demostrar la inexistencia de Dios.

En el testamento otorgado fija las normas a seguir para la creación de la repetida escuela, sostenimiento y administración de la misma, y dispone así mismo las personas que deben ser sus administradores entre las cuales algunas tienen que ser designadas por esta Excma. Corporación. Por todo lo expuesto, y por estar próxima la fecha en que deben ser cumplidas las disposiciones testamentarias del señor Colom y Víctor, toda vez que han dejado de existir casi todos los herederos usufructuarios del mismo, los Concejales que suscriben tiene el honor de proponer al Cabildo Excmo. las siguientes proposiciones por si tiene a bien aprobarla.

$1^{a}$ : Que se nombre una Comisión del seno del municipio para que en unión del abogado asesor del mismo, don José María Pérez Halcón, se personen en la testamentaria del señor Colom y propongan al Ayuntamiento lo procedente sobre dicho asunto.

$2^{\circ}$ : Que, con la mayor brevedad, se efectúen las diligencias necesarias (una vez conocido el informe que en la proposición primera se menciona) para que se cumpla la voluntad del testador y se dé la aplicación debida a dicha donación.

En la sesión celebrada por la Corporación Municipal el 14 de septiembre de 1934, se dio lectura a la moción anterior y se aprobó, con el voto en contra del concejal García Romero. En el acuerdo no figuran los detalles de la misma, tan sólo se limita a reflejar la voluntad del consistorio para «que se nombre una Comisión para que con el letrado Pérez Halcón se personen en la testamentaría de don José Colom, propongan al Ayuntamiento lo procedente y se efectúe la diligencia necesaria para que se cumpla la voluntad del referido señor, y se dé aplicación debida a la donación que de su fortuna hizo a esta población».

No hemos localizado más informaciones sobre esta cuestión en el Archivo Municipal y se desconoce, a día de hoy, por tanto, si este acuerdo tuvo algún fruto.

\section{La Junta Provincial de Beneficencia vuelve a la carga ${ }^{44}$}

Una vez fallecido José Colom Matheos ${ }^{45}$ y otros miembros de la familia, herederos usufructuarios del legado, el gobernador civil de Cádiz, Manuel Urbina Carrera, reencarnándose en su antecesor y retomando su actuación de 1914, desempolvó el expediente que la Junta Provincial de Beneficencia había tramitado ante el Estado para tratar, en una coyuntura política más favorable, de hacerse con alguna parte del pastel.

\footnotetext{
${ }^{44}$ ARCHIVO HISTÓRICO PROVINCIAL DE CÁDIZ (AHPC): Gobierno Civil. Beneficencia, Legado de José Colom Victor.

45 José Colom Matheos nació en 1882, hijo del matrimonio celebrado en 1879 por Francisco, hermano de José Colom Víctor y Regla Matheos Castelló. Ella era hija de José Matheos Valdivieso (fallecido en 1878, abogado de Sanlúcar de esta ciudad, con 55 años, vecino de la calle Santo Domingo, 28) y de Paz Porrata Arizón.
} 
Así, en junio de 1955, Urbina Carrera, siguiendo las instrucciones emanadas del propio ministro de Gobernación de aquella época, Blas Pérez, se dirige al alcalde de Sanlúcar para informarle que, «en cumplimiento de lo dispuesto en la Instrucción de 24 de julio de 1913» por la que se ejercía el protectorado del Gobierno en la Beneficencia Docente Particular, se estaban investigando los bienes de la testamentaría de Colom. Se habían enviado comunicaciones dirigidas al registrador de la propiedad de Sanlúcar, al notario-archivero de Protocolos, así como a los directores de los Bancos Central, Hispano Americano, de Bilbao, y Caja de Ahorros y Monte de Piedad, todos ellos de Sanlúcar. El alcalde, por su parte, también debía comprobar e investigar la existencia de tales bienes y «cuantos datos y noticias puedan ser interesantes a los fines que se persiguen».

Al notario archivero de Protocolos le pide el Gobernador que compruebe la existencia de «operaciones testamentarias derivadas del fallecimiento de dicho señor. O si con relación a la sucesión testada del mismo se ha otorgado algún instrumento público, por lo que se pueda venir en conocimiento de los bienes dejados por el citado causante».

En el expediente conservado se incluyen varias copias de un completo informe elaborado, al parecer (ya que no está firmado), por los asesores jurídicos del Ministro de la Gobernación, en la Dirección General de lo Contencioso. Es un poco contradictorio, ya que el informe desautoriza "por el momento" la intervención del Estado en este asunto, dado el carácter "ilegal" de la Fundación que propugnó Colom Víctor, a tenor de las leyes de la época en la que la religión católica era la única verdadera, oficial y reconocida por el Estado franquista ${ }^{46}$. Aun a pesar de esta desautorización, el expediente siguió su curso y se estuvieron investigando, con los poderosos medios burocráticos de la época, la existencia de los herederos de segunda generación de la familia, para, en el caso de que no existieran o renunciaran a su derecho, pudiera la Junta Provincial de Beneficencia de Cádiz incautarse de los bienes al declararse «ilegales» los fines de la Fundación creada por Colom Víctor. El asunto quedó así, una vez más, empantanado.

\section{Conclusión}

Es evidente que en la coyuntura social y política actual no puede estimarse, bajo ningún concepto, que una Fundación laica que propugne la falsedad de cualquier religión sea «atentatoria contra la moral y las buenas costumbres». Aun a pesar de ello, y del tiempo

\footnotetext{
46 Se cita el Art. $6^{\circ}$ de la Ley de 17 de julio de 1945, que aprueba el Fuero de los Españoles, que establecía que la religión del Estado Español es la Católica, Apostólica, Romana. Así que dicha cláusula «debía ser considerada, siempre, como atentatoria a las Leyes y a la Moral».
} 
transcurrido en Democracia, el testamento de Colom Víctor no ha sido cumplido por las instituciones, y sus propiedades se han ido repartiendo en los últimos años entre particulares con la connivencia del Estado, que no ha hecho prácticamente nada por incorporarlo a su Patrimonio. Según cálculos estimatorios, el montante económico de su legado podría superar el millón de euros en valores del mercado actual.

José Colom Víctor es un personaje hoy olvidado pero que en su época representó un modelo de coherencia ideológica. Por ello debemos necesariamente definir la figura de Colom como la de un adelantado a su tiempo. Vivió muy cómodamente desde el punto de vista material al disponer de bienes suficientes para hacerlo, pero desde el punto de vista de su ética y de su ejemplo eligió un camino muy incómodo y lleno de amargos sinsabores. Representante y apóstol del republicanismo militante y comprometido, ideólogo del librepensamiento y guerrero del movimiento anticlerical, se enfrentó a personajes locales muy poderosos que jamás le entendieron ni mucho menos compartieron sus pensamientos y forma de vida. Aunque sí parece que le respetaron por su cualidad de intelectual proveniente de una familia de rancio abolengo.

El testamento dejado por Colom Víctor está perfectamente detallado y su ejecución muy programada. Parece como si el otorgante, consciente de que se tardarían aún varios años en conseguir que la sociedad en la que vivía cambiara de mentalidad, primero quiso dejarle una buena "jubilación” a su asistenta, como así ocurrió, sin que en ningún momento pudiera transmitir o vender los bienes. Después, previniendo posibles ruinas familiares, quiso que sus sobrinos y sus hijos disfrutaran de esas riquezas y rentas. Y, tercero, tras un largo período de tiempo previsto y calculado con precisión por el testador, se procedería a la constitución de esa Fundación Laica que sería quien definitivamente se haría con la propiedad de todos los bienes para los fines educativos y culturales que dejó mandados. Por desgracia, Colom no pudo adivinar o prever que una Guerra Civil destrozaría todos esos ideales que él tan dignamente contribuyó a crear y que todo su proyecto fundacional se sepultaría bajo los ladrillos de la intolerancia y la represión militar, política y religiosa.

Parece que, tras haber transcurrido más de cien años de su fallecimiento, ha llegado el momento ya de poner en marcha esta Fundación y con ella cumplir la voluntad de don José Colom Víctor. En caso contrario, debería ser el Estado el que tomase definitivamente posesión de estos bienes, en calidad de mostrencos, antes de que terminen cayendo todos en manos privadas, como ya ha ocurrido con algunos de ellos, desvirtuando así la generosa e idealista voluntad del testador. 